\title{
An Investigation of Functional Similarities between the Sarcoplasmic Reticulum and Platelet Calcium-Dependent Adenosinetriphosphatases with the Inhibitors Quercetin and Calmidazoliun ${ }^{\dagger}$
}

\author{
Thomas H. Fischer, ${ }^{*}$ Kevin P. Campbell, ${ }^{\S}$ and Gilbert C. White, $\mathrm{II}^{\sharp}$ \\ Departments of Medicine and Biochemistry, Center for Thrombosis and Hemostasis, The Dental Research Center. The \\ University of North Carolina, Chapel Hill, North Carolina 27514, and Department of Physiology and Biophysics, The \\ University of Iowa, Iowa City, Iowa 52242 \\ Received October 21, 1986; Revised Manuscript Received June 16, 1987
}

\begin{abstract}
The platelet and skeletal sarcoplasmic reticulum calcium-dependent adenosinetriphosphatases $\left(\mathrm{Ca}^{2+}\right.$-ATPases) were functionally compared with respect to substrate activation by steady-state kinetic methods using the inhibitors quercetin and calmidazolium. Quercetin inhibited platelet and sarcoplasmic reticulum $\mathrm{Ca}^{2+}$-ATPase activities in a dose-dependent manner with $\mathrm{IC}_{50}$ values of 25 and $10 \mu \mathrm{M}$, respectively. Calmidazolium also inhibited platelet and sarcoplasmic reticulum $\mathrm{Ca}^{2+}$-ATPase activities, with half-maximal inhibition measured at 5 and $\mu \mathrm{M}$, respectively. Both inhibitors also affected the calcium transport acuity of intact platelet microsomes at concentrations similar to those which reduced $\mathrm{Ca}^{2+}$-ATPase activity. These inhibitors were then used to examine substrate ligation by the platelet and sarcoplasmic reticulum calcium pump proteins. For both $\mathrm{Ca}^{2+}$-ATPase proteins, quercetin has an affinity for the $\mathrm{E}-\mathrm{Ca}_{2}$ (fully ligated with respect calcium at the exterior high-affinity calcium binding sites, unligated with respect to ATP) conformational state of the protein that is approximately 10 -fold greater than for other conformational states in the hydrolytic cycle. Quercetin can thus be considered a competitive inhibitor of the calcium pump proteins with respect to ATP. In contrast to the effect of quercetin, calmidazolium interacts with the platelet and sarcoplasmic reticulum $\mathrm{Ca}^{2+}$-ATPases in an uncompetitive manner. The dissociation constants for this inhibitor for the different conformational states of the calcium pump proteins were similar, indicating that calmidazolium has equal affinity for all of the reaction intermediates probed These observations indicate that the substrate ligation processes are similar for the two pump proteins. This supports the concept that the hydrolytic cycles of the two proteins are comparable.
\end{abstract}

$\mathrm{M}$ icrosomal fractions from human blood platelets transport calcium in an energy-dependent manner; Influx of calcium requires adenosine $5^{\prime}$-triphosphate (ATP), ${ }^{1}$ is accompanied by the release of inorganic phosphate, is inhibited by agents that inhibit calcium-pumping $\mathrm{Ca}^{2+}$-ATPases, and is enhanced by membrane-permeable calcium binding anions (Statland et al., 1969; Robblee et al., 1973; Enouf et al., 1984; Adunyah \& Dean, 1986). $\mathrm{A} \mathrm{Ca}^{2+}$-ATPase activity can be demonstrated functionally (Robblee ct al., 1973; Rodan \& Feinstein, 1976; Kaser-Glanzmann et al., 1978; Javors et al., 1982; Dean \& Sullivan, 1982) and immunologically (Dean, 1981; Fischer et al., 1985) in the microsome fraction. The $\mathrm{Ca}^{2+}$-ATPase and transport activities in microsomes copurify with platelet subcellular fractions that contain cyclooxygenase activity (Menashi et al., 1982; Carey et al., 1982), a marker for the dense tubular system. This observation and histochemical studies localizing a $\mathrm{Ca}^{2+}$-ATPase activity to the dense tubular astern (Cutler et al., 1978) have led to the suggestion that the dense tubular system is a calcium-regulating organelle in platelets, like the sarcoplasmic reticulum of muscle (Ikemoto, 1982).

We have been interested in the $\mathrm{Ca}^{2+}$-ATPase of the platelet dense tubular system and its functional relationship to the sarcoplasmic reticulum $\mathrm{Ca}^{2+}$-ATPase. Both proteins have molecular weights of 103000 as estimated by $\mathrm{NaDodSO}_{4}$

\footnotetext{
${ }^{\dagger}$ This work was supported by National Institutes of Health Grants HL26309 (Specialized Center of Research in Thrombosis) (G.C.W. and T.H.F.) and NS-18814 (K.P.C.). K.P.C. is an Established Investigator of the American Heart Association.

* Address correspondence to this author.

* The University of North Carolina.

$\S$ The University of Iowa.
}

electrophoresis (Dean, 1981; Fischer et al., 1985). The platelet $\mathrm{Ca}^{2+}$-ATPase cross-reacts with polyclonal antibodies to the sarcoplasmic reticulum $\mathrm{Ca}^{2+}$-ATPase (Dean \& Sullivan, 1982; Fischer et al., 1985). The platelet and sarcoplasmic reticulum proteins are also activated by calium and ATP over similar concentration ranges (Javors et al., 1982; Ikemoto, 1982), although a direct substrate activation comparison of the two proteins has not been performed. The platelet $\mathrm{Ca}^{2+}$-ATPase is reported to form a phosphoaspartyl intermediate (Le Peuch et al., 1983; Enyedi et al., 1986), as does the sarcoplasmic reticulum $\mathrm{Ca}^{2+}$-ATPase (Martonosi, 1969). Despite these similarities, there is evidence that the two pump proteins are structurally different. Structural differences have been noted between the two $\mathrm{Ca}^{2+}$-ATPases both with limited proteolysis (Fischer et al., 1985) and with anti-sarcoplasmic reticulum $\mathrm{Ca}^{2+}$-ATPase monoclonal antibody probe (Zubrzycka-Gaarn et al., 1984) studies.

The present study was undertaken to compare the catalytic mechanisms of the platelet and sarcoplasmic reticulum calcium pump proteins. The hydrolytic cycle of the sarcoplasmic reticulum $\mathrm{Ca}^{2+}$-ATPase has been characterized as abbreviated in Figure 1 (De Meis \& Vianna, 1979; Inesi et al., 1980; Tanford et al., 1985). Upon exposure to calcium and ATP, ligation of two calcium ions and ATP occurs in a random manner with the most favorable ligation sequence determined

\footnotetext{
${ }^{1}$ Abbreviations: $\mathrm{Ca}^{2+}$-ATPase, calcium-dependent adenosinetriphosphatase; ATP, adenosine 5'-triphosphate; EGTA, ethylene glycol bis $\left(\beta\right.$-aminoethyl cther)- $N, N, N^{\prime}, N^{\prime}$-tetraacetic acid; $\mathrm{PbCH}_{2} \mathrm{SO}_{2} \mathrm{~F}$, phenylmethanesulfonyl nuoride; $\mathrm{NaDodSO}_{4}$, sodium dodecyl sulfate; Tns, tris(hydroxymethyl)aminomethane; SAS, statistical analysis system.
} 


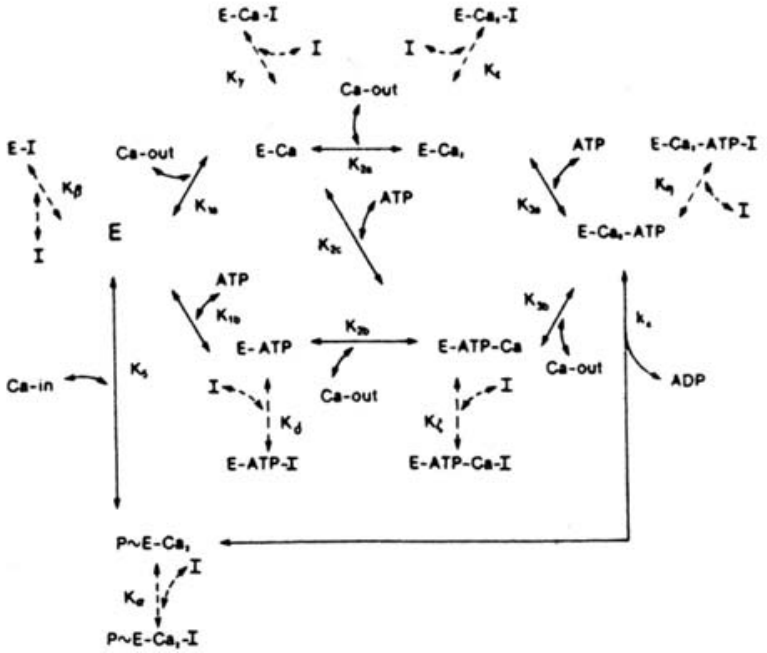

FIGURE 1: Reaction scheme used for the derivation of eq 1 and the analysis of experimental data.

by the concentration of ligands. Upon full substrate ligation of the protein, the ATP $\gamma$-phosphate group is then transferred to an aspartyl residue. Subsequent conformational changes in the $\mathrm{Ca}^{2+}$-ATPase result in calcium translocation to the lumenal side of the protein and hydrolysis of the aspartylphosphate bond. In this study, the hydrolytic cycles of the platelet and sarcoplasmic reticulum proteins have been examined by comparing the substrate activation properties of the two calcium pump proteins in the presence and absence of quercetin and calmidazolium (R23471). Quercetin is a flavonoid which has been previously shown to be a competitive inhibitor of ATP binding to the $\mathrm{Ca}^{2+}$-ATPase at low ATP concentrations (Shoshan et al., 1980; Shoshan \& MacLennan, 1981). Calmidazolium is a derivative of the antimycotic miconazole which is a potent inhibitor of calcium- and calmodulin-dependent enzymes. It has been shown to inhibit the $\mathrm{Ca}^{2+}$-ATPase activity of sarcoplasmic reticulum in an uncompetitive manner, perhaps through an effect on membrane phospholipids (Anderson et al., 1984). We have used these two inhibitors to compare the catalytic cycles of the platelet and sarcoplasmic Teticulum enzymes.

\section{MATERIALS AND METHODS}

All chemicals were reagent grade. Quercetin, calmidazolium, pyruvate kinase, and lactate dehydrogenase were obtained from Sigma Chemical Co. Water was distilled and deionized and contained less than $5 \mathrm{nM}$ calcium. The procedure of Peterson (1977) was used to measure protein concentration. Free $\mathrm{Ca}^{2+}$ and Mg-ATP concentrations were calculated with the methods of Fabiato and Fabiato (1979) and Vianna (1975), respectively.

Preparation of Microsomes. The isolation of platelet microsomes was described in detail elsewhere (White \& Raynor, 1982). Briefly, washed human platelets, obtained from 3-12-h outdated platelet concentrates or from freshly drawn blood, were subjected to sonication, followed by centrifugation to isolate a $14000-40000 \mathrm{~g}$ microsomal fraction. The final microsomal pellet from outdated platelets was suspended in "storage medium" [94 mM KCl, 5 mM MgCl, $50 \mu \mathrm{M} \mathrm{CaCl}_{2}$, $20 \%$ (w/v) glycerol, $0.1 \mathrm{mM} \mathrm{PhCH}_{2} \mathrm{SO}_{2} \mathrm{~F}$, and $20 \mathrm{mM}$ Tris/Tris-HCl, $\mathrm{pH}$ 7.75] at a protein concentration of 5-10 $\mathrm{mg} / \mathrm{mL}$. For studies of calcium transport activity, microsomes were used the day of preparation. For studies of $\mathrm{Ca}^{2+}$-ATPase activity, microsomes were stored at $-80{ }^{\circ} \mathrm{C}$ until use. Microsomes stored at $-80{ }^{\circ} \mathrm{C}$ retain full $\mathrm{Ca}^{2+}$-ATPase activity but are leaky to calcium. ${ }^{2}$ The $\mathrm{Ca}^{2+}$-ATPase activity of these microsomes is the same in the presence and absence of ionophore A23187, indicating that there is no calcium gradient across the membrane.

Sarcoplasmic reticulum microsomes were prepared from adult rabbit skeletal muscle according to the method of MacLennan (1970) as modified by Campbell and MacLennan (1981) in the presence of the following protein inhibitors: pepstatin A (1 $\mu \mathrm{M})$, antipain $(1 \mu \mathrm{M})$, leupeptin $(1.4 \mu \mathrm{M})$, chymostatin $(0.7 \mu \mathrm{g} / \mathrm{mL})$, benzamidine $(0.8 \mathrm{mM})$, aprotinin (125 units/mL), iodoacetamide $(1 \mathrm{mM})$. and $\mathrm{PhCH}_{2} \mathrm{SO}_{2} \mathrm{~F}$ $(0.2 \mathrm{mM})$. Sarcoplasmic reticulum microsomes were stored at $-80{ }^{\circ} \mathrm{C}$ at a protein concentration of $10-20 \mathrm{mg} / \mathrm{mL}$ in 0.25 M sucrose, $1.0 \mathrm{mM}$ histidine, and $10 \mathrm{mM}$ Tris/Tris-HCl, $\mathrm{pH}$ 8.0.

$\mathrm{Ca}^{2+}$-ATPase Activity. ATPase activity was measured spectrophotometrically with a coupled enzyme system in which ATP hydrolysis was coupled to NADH oxidation through the activities of pyruvate kinase and lactate dehydrogenase (Norby, 1971). The ATPase assays were conducted at $24{ }^{\circ} \mathrm{C}$ in “ATPase medium” [94 mM KCl, 5 mM $\mathrm{MgCl}_{2}, 100 \mu \mathrm{M}$ $\mathrm{CaCl}_{2}$, $0.1 \mathrm{mM}$ NADH. $4.2 \mathrm{mM}$ phospho(enol)pyruvate, 10 units $/ \mathrm{mL}$ lactate dehydrogenase, 10 units/mL pyruvate kinase, and $20 \mathrm{mM}$ Tris/Tris-HCl, $\mathrm{pH}$ 7.0] that contained various amounts of ATP and EGTA. The microsomal protein concentration during the ATPase activity measurement was 80 $\mu \mathrm{g} / \mathrm{mL}$ with platelet microsomes and $3 \mathrm{ug} / \mathrm{mL}$ with the sarcoplasmic reticulum material. The inhibitors quercetin and calmidazolium were introduced into the assay system by diluting ethanol stock suspensions or neat ethanol (for control measurements) 100-fold into the "ATPase medium". $\mathrm{Ca}^{2+}$-ATPase activity was defined as the total ATPase activity minus the ATPase activity in the presence of 2 mM EGTA.

Calcium Transport. Uptake of calcium by microsomes was measured by suspending the microsomal pellets in "homogenizing medium" (10 mM oxalate, $30 \mathrm{mM} \mathrm{KCl,} 5 \mathrm{mM}$ $\mathrm{MgCl}_{2}$, and $20 \mathrm{mM}$ Tris/Tris-HCl, $\mathrm{pH}$ 7.0) at a protein concentration of $2-5 \mathrm{mg} / \mathrm{mL}$ - The calcium transport assay was initiated by diluting the microsomal pellet suspension 10-fold into "incubation medium” (94 mM KCl, $5 \mathrm{mM} \mathrm{MgCl}_{2}$, $100 \mu \mathrm{M} \mathrm{CaCl}_{2}$, (with $0.03 \mathrm{~mol}$ of $45 \mathrm{Ca}^{2+} / \mathrm{mol}$ of $\mathrm{Ca}^{2+}$ ), $2 \mathrm{mM}$ ATP, and $20 \mathrm{mM}$ Tris/Tris-HCl, $\mathrm{pH}$ 7.0]. Internalized calcium was measured as a function of time by placing $100-\mu \mathrm{L}$ portions of the uptake mixture on micropore filters (Millipore type HA, $0.45-\mu \mathrm{m}$ pore size) attached to a vacuum filtration apparatus. Filters were subsequently washed with two $5-\mathrm{mL}$ portions of ice-cold $150 \mathrm{mM} \mathrm{NaCl}$ and then placed in $5 \mathrm{~mL}$ of Aquasol-2 for liquid scintillation counting.

Data Analysis. Steady-state substrate activation methods were used to measure equilibrium constants ( $K_{3 \mathrm{a}}, K_{2 \mathrm{~b}}, K_{3 \mathrm{~b}}, K_{\eta}$ $K_{\varepsilon}$ and $K_{\zeta}$ ) for the reaction steps related to calcium and ATP ligation by the calcium pump proteins. Transient state kinetic methods were not utilized because of the trace nature of the platelet $\mathrm{Ca}^{2+}$-ATPase. The analysis is based on the reaction model presented in Figure 1 which is a modification of the hydrolytic cycle for the Sarcoplasmic reticulum $\mathrm{Ca}^{2+}$-ATPase as originally proposed by De Meis and Vianna (1979). In Figure 1, substrate ligation occurs in a random order, with the preferred pathway (or combination of pathways) being de-

\footnotetext{
${ }^{2}$ Microsomes stored at $-80{ }^{\circ} \mathrm{C}$ retain full $\mathrm{Ca}^{2+}$-ATPase activity but do not sequester calcium. Since the calcium activation curves for freshly prepared (in the presence of A231S7) and frozen microsomes are the same (T. H. Fischer and G. C. While, unpublished observations), the most likely explanation for the failure of frozen microsomes to sequester calcium is that the membrane is leaky to calcium.
} 
termined by the concentration of ATP and calcium. This type of ligation scheme has been proposed (Inesi et al., 1980; Tanford et al., 1985; Reynolds et al., 1985; Gould et al., 1986) to account for transient and steady-state kinetic measurements (Neet \& Green, 1977; Inesi et al., 1980; Moller et al., 1980; Gould et al., 1986) involving substrate activation of the sarcoplasmic reticulum $\mathrm{Ca}^{2+}$-ATPase. The scheme in Figure 1 includes only steps that can be probed by varying calcium and ATP concentration on a steady-state time scale. Thus, the $\mathrm{E}^{*}$ to E transition described by DeMais and Vianna (1979) and the sequence of reactions connecting the $\mathrm{P} \sim \mathrm{E} \cdot \mathrm{Ca}_{2}$ and E stales are not explicitly detailed. The step leading to ADP formation is depicted as irreversible because the ADP concentration in our system was essentially zero in the presence of the ATP regeneration system. Also, internal and external calcium concentrations were equated since leaky microsomes were used. ${ }^{2}$ Finally, the effects of quercetin and calmidazolium on the $\mathrm{Ca}^{2+}$-ATPases were assumed to occur through reversible binding of the inhibitors to various conformational states of the protein, yielding inactive protein-drug complexes.

The reaction sequence in Figure 1 was used to calculate values for some of the equilibrium constants and to generate functions which approximate the substrate activation curves. Using the standard expressions for the equilibrium constants in Figure $1\left(K_{1 \mathrm{a}}, K_{1 \mathrm{~b}}, K_{2 \mathrm{a}}, K_{2 \mathrm{~b}}, K_{2 \mathrm{c}}, K_{3 \mathrm{a}}\right.$, and $K_{3 \mathrm{~b}}$, which were defined as association constants, and $K_{5}, K_{\alpha}, K_{\beta}, K_{\gamma}, K_{\delta}, K_{\varepsilon}$, $K_{\zeta}$, and $K_{\eta}$, which were defined as dissociation constants), we can express the total enzyme concentration $\left[\mathrm{E}^{0}\right]$ as

$$
\begin{aligned}
& {\left[\mathrm{E}^{0}\right]=\left(1+[\mathrm{I}] / K_{\alpha}\right)\left[\mathrm{P} \sim \mathrm{E} \cdot \mathrm{Ca}_{2}\right]+\left(1+[\mathrm{I}] / K_{\beta}\right)[\mathrm{E}]+} \\
& \left(1+[\mathrm{I}] / K_{\gamma}\right)[\mathrm{E} \cdot \mathrm{Ca}]+\left(1+[\mathrm{I}] / K_{\delta}\right)[\mathrm{E} \cdot \mathrm{ATP}]+(1+
\end{aligned}
$$$$
\left.[\mathrm{I}] / K_{\varepsilon}\right)\left[\mathrm{E} \cdot \mathrm{Ca}_{2}\right]+\left(1+[\mathrm{I}] / K_{\zeta}\right)[\mathrm{E} \cdot \mathrm{ATP} \cdot \mathrm{Ca}]+
$$

$$
\left(1+[\mathrm{I}] / K_{\eta}\right)\left[\mathrm{E} \cdot \mathrm{Ca}_{2} \cdot \mathrm{ATP}\right]
$$

and expressions for the velocity of ADP generation ( $V$ and $\left.V_{\text {max }}\right)$ are

$$
\begin{gathered}
V=k_{4}\left[\mathrm{E} \cdot \mathrm{Ca}_{2} \cdot \mathrm{ATP}\right] \\
V_{\max }=k_{4}\left[\mathrm{E}^{0}\right]
\end{gathered}
$$

where $k_{4}$ is a rate constant. This yields the equation for the normalized reciprocal reaction velocity $(1 / V)$ :

$$
\begin{gathered}
1 / V=V_{\max } / V=\left(1+[\mathrm{I}] / K_{\varepsilon}\right) / K_{3 \mathrm{a}}[\mathrm{ATP}]+(1+ \\
\left.[\mathrm{I}] / K_{\zeta}\right) / K_{3 \mathrm{~b}}[\mathrm{Ca}]+\left(1+[\mathrm{I}] / K_{\gamma}\right) / K_{2 \mathrm{a}} K_{3 \mathrm{a}}[\mathrm{Ca}][\mathrm{ATP}]+ \\
\left(1+[\mathrm{I}] / K_{\delta}\right) / K_{2 \mathrm{~b}} K_{3 \mathrm{~b}}[\mathrm{Ca}]^{2}+ \\
\left(1+[\mathrm{I}] / K_{\beta}\right) / K_{1 \mathrm{a}} K_{2 \mathrm{a}} K_{3 \mathrm{a}}[\mathrm{Ca}]^{2}[\mathrm{ATP}]+ \\
\left(1+[\mathrm{I}] / K_{\alpha}\right) / K_{5} K_{1 \mathrm{a}} K_{2 \mathrm{a}} K_{3 \mathrm{a}}[\mathrm{ATP}]+(1+[\mathrm{I}]) / K_{\eta}(1)
\end{gathered}
$$

where $[\mathrm{Ca}]$ refers to the free $\mathrm{Ca}^{2+}$ concentration and $[\mathrm{ATP}]$ refers to the concentration of $\mathrm{Mg} \cdot \mathrm{ATP}$.

ATP activation data were used to estimate the values of $K_{3 \mathrm{a}}$ and $K_{\varepsilon}$ The ATP activation experiments were performed with a fixed free calcium concentration of $78 \mu \mathrm{M}$. At this concentration, eq 1 can be approximated as

$$
1 / V \simeq \frac{1+[\mathrm{I}] K_{\varepsilon}}{K_{3 \mathrm{a}}[\mathrm{ATP}]}+(1+[\mathrm{I}]) / K_{\eta}
$$

On the basis of the equilibrium constant estimated by Inesi et al. (1980), each term that has been ignored in obtaining eq 2 from eq 1 contributes less than $1 \%$ to the value of $1 / V$. These approximations reflect the predominance of the pathway in Figure 1 involving $K_{1 \mathrm{a}}, K_{2 \mathrm{a}}$, and $K_{3 \mathrm{a}}$ at high calcium concentrations. The first derivative of eq 2 with respect to $1 /$ [ATP] gives

$$
\mathrm{d}(1 / V) / \mathrm{d}(1 /[\mathrm{ATP}])=\left(1+[\mathrm{I}] K_{\varepsilon}\right) / K_{3 \mathrm{a}} \equiv S
$$

$$
K_{3 \mathrm{a}}=1 / S \text { at }[\mathrm{I}]=0
$$

and

$$
K_{\varepsilon}=[1] /\left(K_{3 \mathrm{a}} S-1\right)
$$

Least-squares analysis was performed to measure $\mathrm{d}(1 / \mathrm{V}) /$ $\mathrm{d}(1 /[\mathrm{ATP}])$ in the presence and absence of inhibitors and to obtain $K_{3 \mathrm{a}}$ and $K_{\eta}$.

Calcium activation data were used to measure $K_{3 \mathrm{~b}}, K_{2 \mathrm{~b}}, K_{\zeta}$, and $K_{\eta}$ Free calcium concentrations were varied with an EGTA buffer system (Fabiato \& Fabiato, 1979) at a fixed $\mathrm{Mg}$-ATP concentration of $2 \mathrm{mM}$. At this concentration of ATP, the pathway in Figure 1 involving $K_{1 \mathrm{~b}}, K_{2 \mathrm{~b}}$, and $K_{3 \mathrm{~b}}$ is favored, and eq 1 can be approximated as

$$
\begin{array}{r}
1 / \mathrm{V} \simeq 1+[\mathrm{I}] / K_{\eta}+\left(1+[\mathrm{I}] K_{\zeta}\right) / K_{3 \mathrm{~b}}[\mathrm{Ca}]+ \\
\quad\left(1+[\mathrm{I}] K_{\delta}\right) / K_{2 \mathrm{~b}} K_{3 \mathrm{~b}}[\mathrm{Ca}]^{2}
\end{array}
$$

The equilibrium constant estimates of Inesi et al. (1980) indicate that each term that was eliminated from eq 1 contributes less than $1 \%$ to the value of $1 / V$ at $2 \mathrm{mM}$ ATP. The calcium activation data were expressed in terms of $1 / V$ and then fit with a power function to yield numerical values in terms that were zero, first, and second order with respect to $1 /[\mathrm{Ca}]$ :

$$
1 / V=A+B(1 /[\mathrm{Ca}])+C(1 /[\mathrm{Ca}])^{2}
$$

Thus

$$
\begin{gathered}
A=(1+[\mathrm{I}]) / K_{\eta} \\
B=\left(1+[\mathrm{I}] / K_{\zeta}\right) / K_{3 \mathrm{~b}} \\
C=\left(1+[\mathrm{I}] / K_{\delta}\right) / K_{2 \mathrm{~b}} K_{3 \mathrm{~b}}
\end{gathered}
$$

and

$$
\begin{gathered}
K_{\eta}=[\mathrm{I}] /(A-1) \\
K_{3 \mathrm{~b}}=1 / B \text { at }[\mathrm{I}]=0 \\
K_{\zeta}=[\mathrm{I}] /\left(B K_{3 \mathrm{~b}}-1\right) \\
K_{2 \mathrm{~b}}=1 / C K_{3 \mathrm{~b}} \text { at }[\mathrm{I}]=0
\end{gathered}
$$

$K_{\delta}$ was not measured because statistically significant values of $C$ were not obtained in the presence of inhibitors.

Statistical Analysis. Statistical analysis of data, including least-squares analysis and power curve fit, was performed by using the statistical analysis system (SAS) software package (SAS Institute, Cary, NC) and an IBM 4381 mainframe computer. Errors in $A, B, C$, and $S(\Delta A, \Delta B, \Delta C$, and $\Delta S$. respectively) were provided by SAS and were based on $90 \%$ confidence intervals. The errors in $K_{3 \mathrm{a}}, K_{2 \mathrm{~b}}, K_{3 \mathrm{~b}}, K_{\eta}, K_{\zeta}$, and $K_{\varepsilon}\left(\Delta K_{3 \mathrm{a}}, \Delta K_{2 \mathrm{~b}}, \Delta K_{3 \mathrm{~b}}, \Delta K_{\eta}, \Delta K_{\zeta}\right.$, and $\Delta K_{\varepsilon}$, respectively) were calculated from $A, B, C, S, \Delta A, \Delta B, \Delta C$, and $\Delta S$ as follows, with total differential error propagation:

$$
\begin{gathered}
\Delta K_{3 \mathrm{a}}=\Delta S / S^{2} \\
\Delta K_{3 \mathrm{~b}}=\Delta B / B^{2} \\
\Delta K_{2 \mathrm{~b}}=\Delta C / C^{2} K_{3 \mathrm{~b}}+K_{3 \mathrm{~b}} / C K_{3 \mathrm{~b}}{ }^{2} \\
\Delta K_{\varepsilon}=\left[[\mathrm{I}] S /\left(K_{3 \mathrm{a}} S-1\right) 2\right] \Delta K_{3 \mathrm{a}}+\left[[\mathrm{I}] K_{3 \mathrm{a}} /\left(K_{3 \mathrm{a}} \mathrm{S}-1\right) 2\right] \Delta S \\
\Delta K_{\eta}=[\mathrm{I}] \Delta A /(A-1)^{2} \\
\Delta K_{\zeta}=\left[[\mathrm{I}] K_{3 \mathrm{~b}} /\left(K_{3 \mathrm{~b}} B-1\right)^{2}\right] \Delta B+\left[[\mathrm{I}] B /\left(K_{3 \mathrm{~b}} B-1\right)^{2}\right] \Delta K_{3 \mathrm{~b}}
\end{gathered}
$$

\section{RESUlts}

Dose-response curves for the effect of quercetin on platelet and sarcoplasmic reticulum $\mathrm{Ca}^{2+}$-ATPase activity are pres-

Thus 


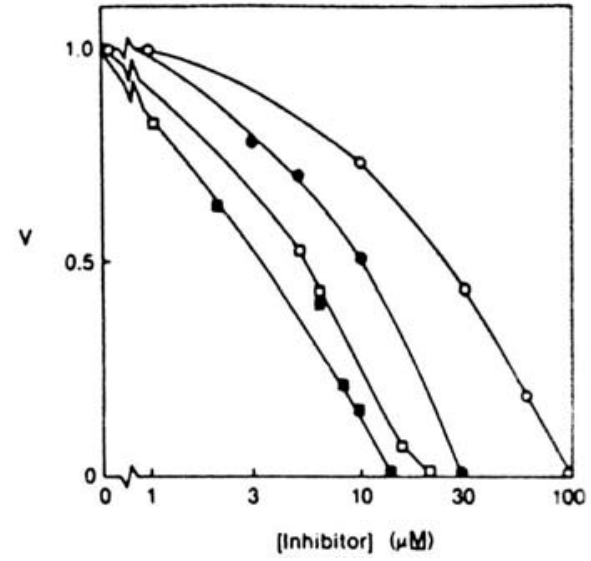

FIGURE 2: Dose-response curve for the effects of quercetin $(\bullet, \circ)$ and calmidazolium $(\square, \boldsymbol{\square})$ on platelet $(\circ, \square)$ and sarcoplasmic reticulum $(\bullet, \mathbf{\square}) \mathrm{Ca}^{2+}$-ATPase activity. $\mathrm{Ca}^{2+}$-ATPase activity $(V)$ was measured as described under Materials and Methods and normalized to the maximum activity in the absence of inhibitors.
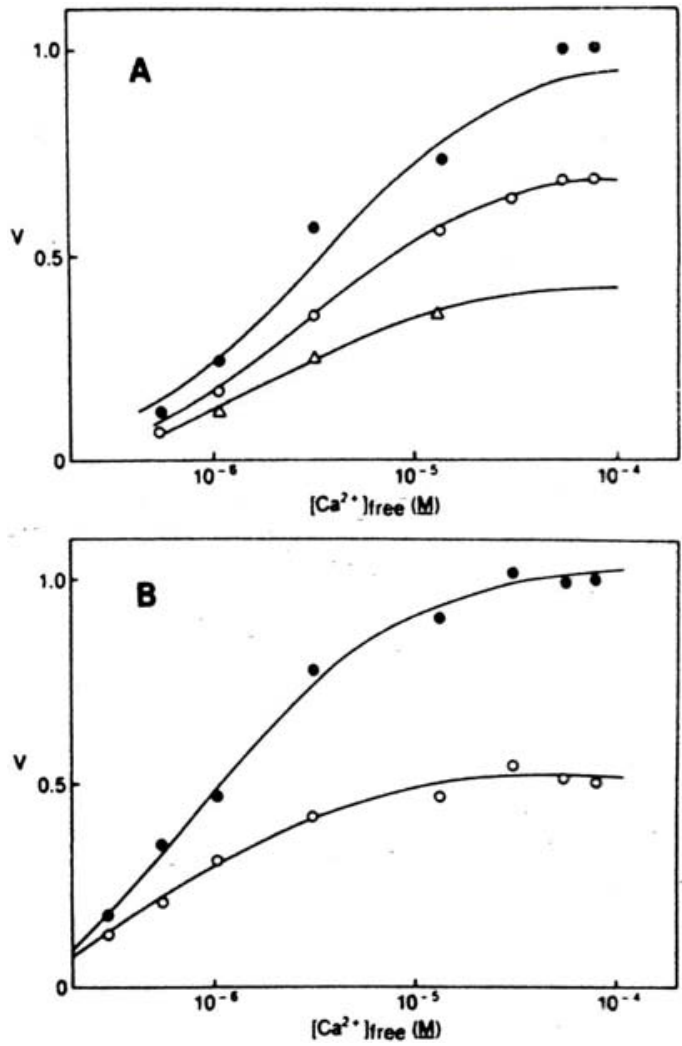

Figure 3: (Panel A) Calcium activation curve for the platelet $\mathrm{Ca}^{2+}$-ATPase in the presence of $0(\bullet), 10(0)$. and $30 \mu \mathrm{M}(\Delta)$ quercetin. (Panel B) Calcium activation curve for the sarcoplasmic reticulum $\mathrm{Ca}^{2+}$-ATPase in the presence of $0(\bullet)$ and $10 \mu \mathrm{M}(\mathrm{\circ})$ quercetin. $\mathrm{Ca}^{2+}$-ATPase activity ( $V$, normalized to the maximal activity in the absence of inhibitor) was measured as detailed under Materials and Methods. The solid curve represents a fit of the data to eq 6 with the parameters in Table I. Free calcium concentration was varied with an EGTA buffer system as detailed under Materials and Methods.

ented in Figure 2. Quercetin inhibited both calcium pump proteins in a dose-dependent manner, with $\mathrm{IC}_{50}$ values of 10 and $25 \mu \mathrm{M}$, respectively, for the sarcoplasmic reticulum and platelet calcium pump proteins. Figure 2 depicts the effect of increasing concentrations of calmidazolium on the platelet and sarcoplasmic reticulum $\mathrm{Ca}^{2+}$-ATPase activities. As with quercetin, calmidazolium inhibited the calcium pump proteins in a dose-dependent manner with $\mathrm{IC}_{50}$ values of 4 and $5 \mu \mathrm{M}$ for the sarcoplasmic reticulum and platelet $\mathrm{Ca}^{2+}$-ATPases, respectively. In both fractions, the inhibition of $\mathrm{Ca}^{2+}$-ATPase
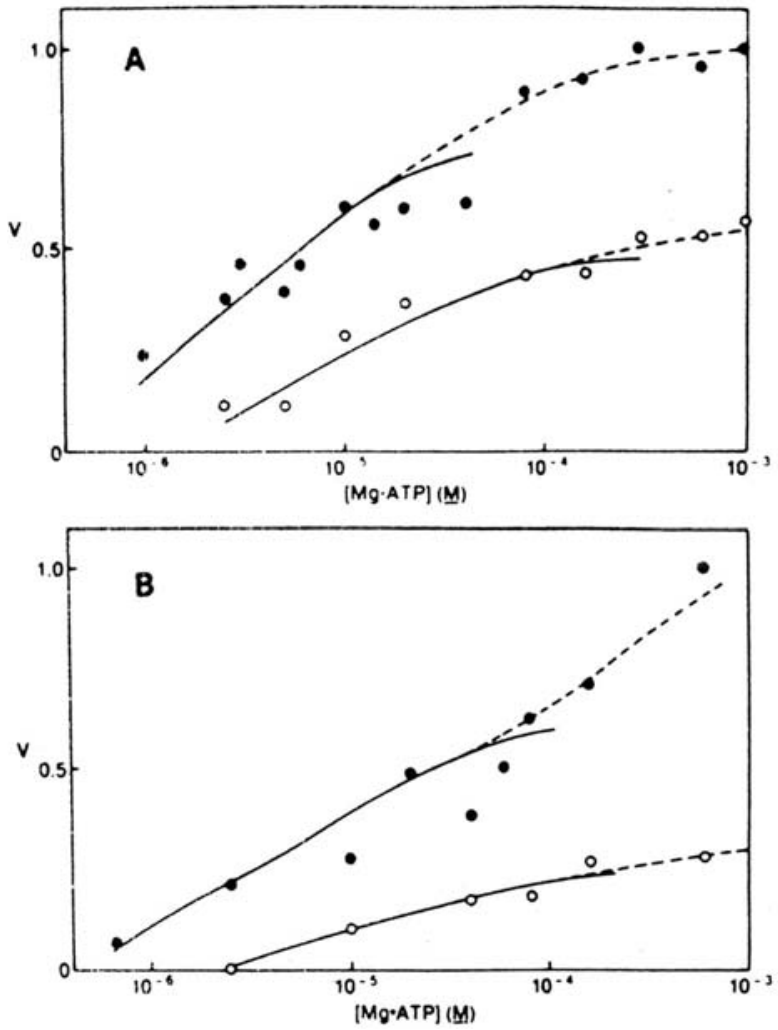

FiguRE 4: (Panel A) Mg-ATP activation curve for the platelet $\mathrm{Ca}^{2+}$-ATPase in the presence of $0(\bullet)$ and $10 \mu \mathrm{M}(\circ)$ quercetin. (Panel B) Mg-ATP activation curve for the sarcoplasmic reticulurn $\mathrm{Ca}^{2+}$-ATPase in the presence of $0(\bullet)$ and $10 \mu \mathrm{M}(0)$ quercetin. $\mathrm{Ca}^{2+}$-ATPasc activity $(V$, normalized to the maximal activity in the absence of inhibitor) was measured as described under Materials and Methods. The solid line represents a fit of the data to eq 2 with the parameters in Table I. The dashed line represents the deviation of data from the fit to eq 2. Mg-ATP concentrations were calculated as detailed under Materials and Methods.

activity by the inhibitors was an inverse function of microsome concentration. The higher the microsome concentration, the greater the $\mathrm{IC}_{50}$ for inhibition of the $\mathrm{Ca}^{2+}$-ATPase activity. Similar effects have been reported by other investigators with these inhibitors and are probably related to the ability of these hydrophobic drugs to partition into the microsomal membranes at high drug:protein ratios.

The effect of quercetin and calmidazolium oh calcium transport by the platelet $\mathrm{Ca}^{2+}$-ATPase was also examined. Both inhibitors reduced the ability of the platelet calcium pump protein to translocate calcium into the interior of the microsomes in a dose-dependent manner with $\mathrm{IC}_{50}$ values similar to those for the inhibition of $\mathrm{Ca}^{2+}$-ATPase activity (data not shown).

The effect of quercetin on the activation of the platelet and sarcoplasmic reticulum $\mathrm{Ca}^{2+}$-ATPases by calcium is presented in Figure 3. With both calcium pump proteins, quercetin was a slightly better inhibitor at saturating free calcium concentrations, this effect being more predominant with the sarcoplasmic reticulum $\mathrm{Ca}^{2+}$-ATPase. Figure 4 shows the effect of quercetin on the activation of $\mathrm{Ca}^{2+}$-ATPases with ATP. The calcium pump protein from both platelet and sarcoplasmic reticulum sources was inhibited to a much greater extent at low ATP concentrations than at higher ATP concentrations. A Lineweaver-Burk plot of the data in Figure 4A is shown in Figure 5 and indicates that quercetin inhibition was somewhat competitive with respect to ATP. However, quercetin cannot be considered a purely competitive inhibitor, since inhibition was not eliminated at very high ATP concentrations. 


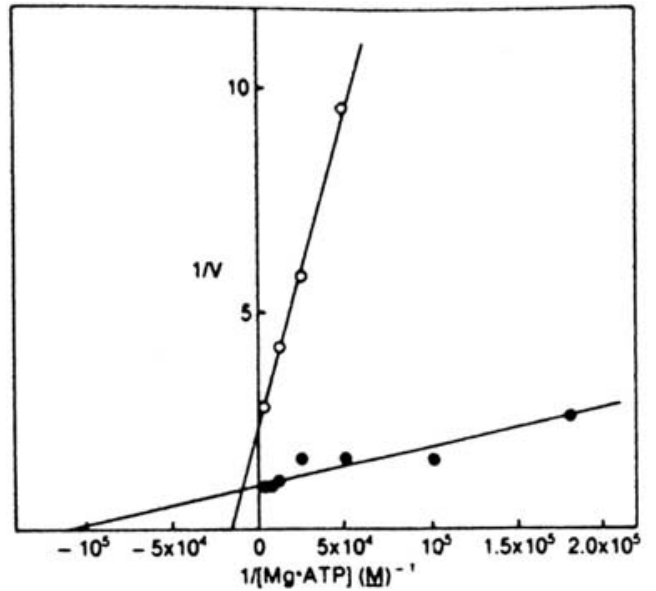

FIGURE 5: Lineweaver-Burk plot for the effect of quercetin on $\mathrm{Mg}$-ATP activation of the platelet $\mathrm{Ca}^{2+}$-ATPase at $0(\bullet)$ and $30 \mu \mathrm{M}$ (o) quercetin. Reciprocal activity $(1 / V)$ is the inverse of the $\mathrm{Ca}^{2+}$-ATPase activity normalized to the maximal value obtained in the absence of inhibitor. Other details arc as described in Figure 4.
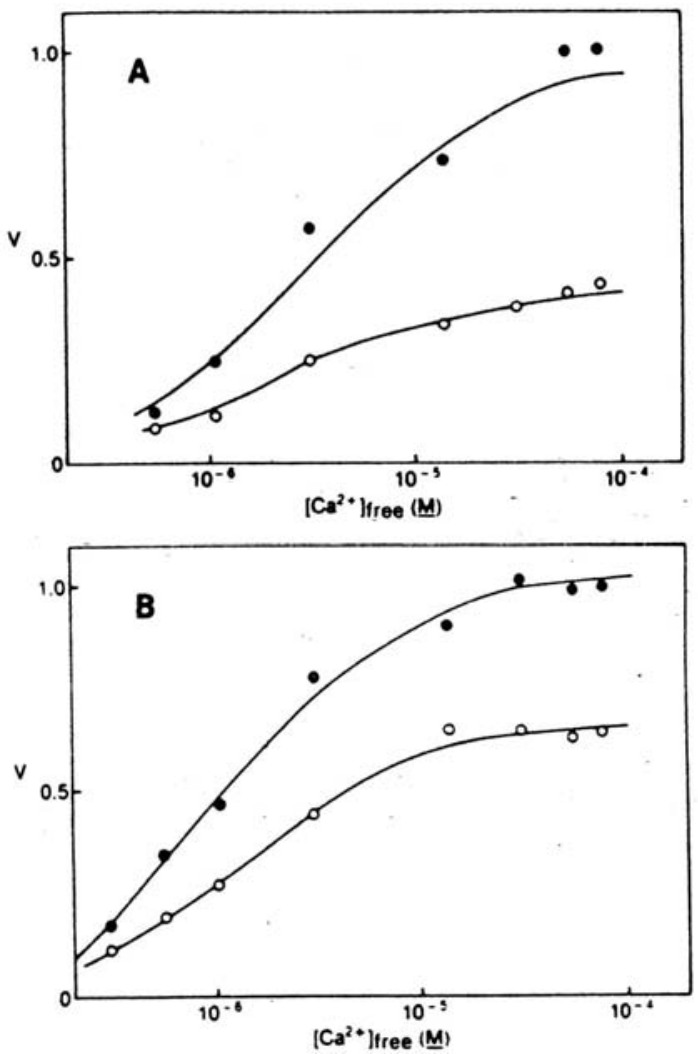

Figure 6: (Panel A) Calcium activation curve for the platelet $\mathrm{Ca}^{2+}$-ATPase in the presence of $0(\bullet)$ and $6 \mu \mathrm{M}(\circ)$ calmidazolium. (Panel B) Calcium activation curve for the sarcoplasmic reticulum $\mathrm{Ca}^{2+}$-ATPase in the presence of $0(\bullet)$ and $2 \mu \mathrm{M}(\mathrm{O})$ calmidazolium. Other details are as in Figure 3.

The effect of calmidazolium on calcium activation of the platelet and sarcoplasmic reticulum $\mathrm{Ca}^{2+}$-ATPases is presented in Figure 6. The degree of inhibition of both calcium pump proteins with calmidazolium was approximately constant over the investigated range of calcium concentrations. Figure 7 depicts the effect of calmidazolium on activation of the $\mathrm{Ca}^{2+}$-ATPases by ATP. At ATP concentrations below approximately $50 \mu \mathrm{M}$, the degree of inhibition of both calcium pump proteins was not highly dependent on ATP concentration. As the ATP concentration was increased above $50 \mu \mathrm{M}$, the additional activation of the $\mathrm{Ca}^{2+}$-ATPase activity that was measured in the absence of inhibitor was largely eliminated by the calmidazolium.
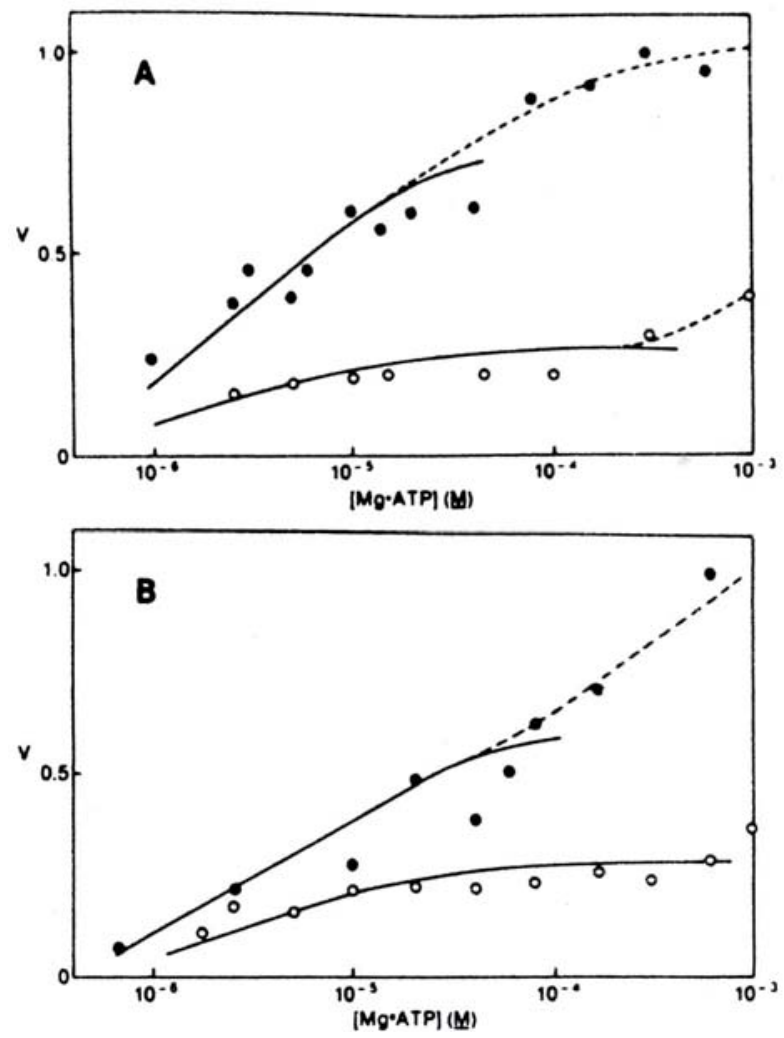

Figure 7: (Panel A) Mg-ATP activation curve for the platelet $\mathrm{Ca}^{2+}$-ATPase in the presence of $0(\bullet)$ and $6 \mu \mathrm{M}(0)$ calmidazolium. (Panel B) Mg-ATP activation curve for the sarcoplasmic reticulum $\mathrm{Ca}^{2+}$-ATPase in the presence of $0(\bullet)$ and $6 \mu \mathrm{M}(\circ)$ calmidazolium. Other details are as in Figure 4.

\begin{tabular}{llll}
\hline Table I & \multicolumn{1}{c}{ platelet } & \multicolumn{1}{c}{ muscle } \\
\hline parameter & \multicolumn{1}{c}{ inhibitor } & \multicolumn{1}{c}{$(6.2 \pm 3.5) \times 10^{6}$} & $(1.8 \pm 1.3) \times 10^{7}$ \\
\hline$K_{\text {ib }}\left(\mathrm{M}^{-1}\right)$ & none & $(3.2 \pm 0.2) \times 10^{5}$ & $(9.2 \pm 0.4) \times 10^{5}$ \\
$K_{3 \mathrm{~b}}\left(\mathrm{M}^{-1}\right)$ & none & $(2.4 \pm 0.1) \times 10^{5}$ & $(1.4 \pm 0.1) \times 10^{5}$ \\
$K_{3 \mathrm{a}}\left(\mathrm{M}^{-1}\right)$ & none & $25 \pm 3$ & $10 \pm 1$ \\
$\mathrm{IC}_{50}(\mu \mathrm{M})$ & quercetin & $27 \pm 5$ & $11 \pm 2$ \\
$K_{\eta}(\mu \mathrm{M})$ & quercetin & $2.4 \pm 0.2$ & $1.3 \pm 02$ \\
$K_{\varepsilon}(\mu \mathrm{M})$ & quercetin & $31 \pm 3$ & $14 \pm 3$ \\
$K_{\zeta}(\mu \mathrm{M})$ & quercetin & $5.0 \pm 0.6$ & $4.0 \pm 0.3$ \\
$\mathrm{IC}_{50}(\mu \mathrm{M})$ & calmidazolium & $4.7 \pm 1.3$ & $3.6 \pm 0.5$ \\
$K_{\eta}(\mu \mathrm{M})$ & calmidazolium & $5.3 \pm 1.0$ & $3.9 \pm 0.3$ \\
$K_{\varepsilon}(\mu \mathrm{M})$ & calmidazolium & $7.4 \pm 2.6$ & $2.2 \pm 1.2$ \\
$K_{\zeta}(\mu \mathrm{M})$ & calmidazolium & & \\
\hline
\end{tabular}

The effect of quercetin and calmidazolium on the $\mathrm{Ca}^{2+}$ ATPases is examined in terms of the reaction scheme presented in Figure 1. This analysis leads to an estimation of apparent dissociation constants for the inhibitors and the $\mathrm{Ca}^{2+}$-ATPases in various conformational states as outlined under Materials and Methods. The analysis using the reaction scheme in Figure 1 also yields functions which approximate the shape of the experimentally determined substrate activation curves (graphs of these curves are presented in Figures 3, 4, 6, and 7 ). The values of the equilibrium constants in Figure 1 for the platelet and sarcoplasmic reticulum calcium pump proteins that are deduced from the data are presented in Table I.

\section{DISCUSSION}

The principal result of this study is that the platelet and sarcoplasmic reticulum $\mathrm{Ca}^{2+}$-ATPases are activated by substrates in a manner that can be modeled by the same catalytic cycle, as depicted in Figure 1. This result is evident by comparing the measurements presented in Table I. The parameters contained in Table I were used in eq 2 and 6 to obtain the solid curves presented in Figures 3,4,6, and 7. A good correlation 
was obtained between the curves generated from eq 6 and the calcium activation data in Figures 3 and 6 . This shows that the sequential addition of calcium to high-affinity binding sites was a reasonable assumption. Upon fitting the calcium activation data to a power series that was zero, first, and second order in $1 /[\mathrm{Ca}]$, it was found that the second-order terms contributed substantially to the calcium activation curves only at very low free calcium concentrations (less than $1(\mu \mathrm{M}$ for the platelet $\mathrm{Ca}^{2+}$-ATPase and less than $0.5 \mu \mathrm{M}$ for the sarcoplasmic reticulum $\mathrm{Ca}^{2+}$-ATPase). The experimental data obtained at free calcium concentrations lower than these values were not accurate enough to obtain precise values for $K_{2 \mathrm{~b}}$. It was thus not worthwhile to use the $K_{2 b}$ values obtained in the presence and absence of inhibitors to calculate $K_{\delta}$. A statistically significant fit between the ATP activation data and eq 2 was obtained only at low ATP concentrations. This deviation potentially reflects the contribution of ATP ligation of E and $\mathrm{E} \cdot \mathrm{Ca}$ states at higher ATP concentrations, which is not accounted for in eq 2 .

A comparison of the association constants for the platelet and sarcoplasmic reticulum $\mathrm{Ca}^{2+}$-ATPases with the first calcium $\left(K_{2 \mathrm{~b}}\right)$, the second calcium $\left(K_{3 \mathrm{~b}}\right)$, and ATP $\left(K_{3 \mathrm{a}}\right)$ in the absence of inhibitors shows that the sarcoplasmic reticulum $\mathrm{Ca}^{2+}$-ATPase has a higher affinity for calcium and a lower affinity for ATP than the platelet calcium pump protein. This reflects the displacement of the sarcoplasmic reticulum $\mathrm{Ca}^{2+}$-ATPase calcium activation curve to lower free calcium concentrations than the platelet $\mathrm{Ca}^{2+}$-ATPase calcium activation curve, and the displacement of the sarcoplasmic reticulum $\mathrm{Ca}^{2+}$-ATPase ATP activation curve. Since the scheme in Figure 1 does not contain the $\mathrm{E}^{*}$ to $\mathrm{E}$ transition (De Meis $\&$ Vianna, 1979), the measured values of $K_{2 \mathrm{~b}}, K_{3 \mathrm{~b}}$, and $K_{3 \mathrm{a}}$ could vary by a factor related to $\left[\mathrm{E}^{*}\right] /[\mathrm{E}]$ from the values estimated with non-steady-state methods.

The dissociation constants in Table I determined for quercetin show that this inhibitor has an approximately 10 -fold higher affinity for the $\mathrm{E} \cdot \mathrm{Ca}_{2}$ state of both the platelet and sarcoplasmic reticulum calcium pump proteins than the other states. In the $\mathrm{E} \cdot \mathrm{Ca}_{2}$ state, the protein has a high-affinity, unoccupied ATP binding site. This is consistent with the experimental observation that quercetin is a mixed competitive inhibitor with respect to ATP activation. The finding that quercetin does interact with other conformational states of the calcium pump proteins, although with an approximately 10fold lower affinity, explains the "mixed" nature of the inhibition that results in the fourth-quadrant intersection of $1 / V$ vs $\mathrm{I} /$ [ATP] lines in Figure 5. The higher affinity of quercetin for the $\mathrm{E} \cdot \mathrm{Ca}_{2}$ state might also explain the tendency for the drug to be a better inhibitor at higher free calcium concentrations (see Figure 3), which favor the $\mathrm{E} \cdot \mathrm{Ca}_{2}$ state.

The nucleoside antagonist effects of quercetin on the platelet and sarcoplasmic reticulum calcium pump proteins reported in this paper are similar to the effect of this inhibitor on the sarcoplasmic reticulum $\mathrm{Ca}^{2+}$-ATPase detailed by Shoshan et al. (1980) and Shoshan and MacLennan (1981). These investigators reported inhibition of $\mathrm{Ca}^{2+}$-ATPase activity with quercetin over a concentration range similar to that obtained in this paper. Also, Shoshan and MacLennan (1981) showed that quercetin competitively inhibited the binding of ATP to the sarcoplasmic reticulum $\mathrm{Ca}^{2+}$-ATPase. That result is consistent with the result presented in this paper (hat quercetin selectively binds to the protein state that contains a high-affinity, unoccupied ATP site $\left(\mathrm{E} \cdot \mathrm{Ca}_{2}\right)$. Since Shoshan and MacLennan reported that quercetin did not reduce thesteady-state level of phosphoenzyme over the drug concen- tration range that inhibits ATP hydrolysis, it is also possible that quercetin binds to phosphorylated forms of the calcium pump protein which have an unoccupied nucleoside site, as in the step described by $\mathrm{K}_{\varepsilon}$ in Figure 1.

In contrast to quercelin, the dissociation constants in Table I for calmidazolium show that this inhibitor docs not preferentially interact with a single conformational state of the platelet or sarcoplasmic reticulum $\mathrm{Ca}^{2+}$-ATPase. The dissociation constants obtained for the interaction of calmidazolium with the various conformational states of the two $\mathrm{Ca}^{2+}-\mathrm{AT}$ Pases were not statistically different, and hypothetical reaction schemes in which there was preferential interaction of calmidazolium with $\mathrm{E} \cdot \mathrm{Ca}_{2}, \mathrm{E} \cdot \mathrm{ATP} \cdot \mathrm{Ca}$, or $\mathrm{E} \cdot \mathrm{Ca}_{2} \cdot \mathrm{ATP}$ conformational states of the calcium pump proteins did not yield substrate activation curves that fit the data in Figures 6 and 7. Since calmidazolium interacted with similar affinity with each conformation of the $\mathrm{Ca}^{2+}$-ATPases (uncompetitive inhibition), calmidazolium inhibition can be modeled by the reaction:

$$
\mathrm{E}(\text { active })+\mathrm{I} \leftrightarrow \mathrm{I} \cdot \mathrm{E}(\text { inactive })
$$

which is equivalent to the scheme in Figure 1 when $K_{\alpha} \cong K_{\gamma}$ $K_{\delta} \cong K_{\varepsilon} \cong K_{\zeta} \cong K_{\eta}$.

An effect of calmidazolium that is not reflected in the parameters in Table $I$ is the ability of the inhibitor to largely eliminate ATP activation of the $\mathrm{Ca}^{2+}$-ATPases at nucleoside concentrations above $100 \mu \mathrm{M}$. This effect occurred with both the platelet and sarcoplasmic reticulum calcium pump proteins and is not reflected in the values of $K_{\gamma}$ in Table I because the ATP activation curves could only be fitted to the form of eq 2 at ATP concentrations lower than $100 \mu \mathrm{M}$. The elimination of ATP activation above approximately $100 \mu \mathrm{M}$ in the presence of calmidazolium could result from a drug-induced shift in equilibriums $K_{1 \mathrm{~b}}$ and $K_{2 \mathrm{c}}$ through either a direct effect or distal-linked function (Tanford et al., 1985) effects. Even in the absence of calmidazolium, eq 2 fails to account for ATP activation data above $100 \mu \mathrm{M}$. This probably arises from the contribution of steps described by $K_{1 \mathrm{~b}}$ and $K_{2 \mathrm{c}}$ in Figure 1 at higher ATP concentrations.

The results of the experiments reported in this paper show that there are functional similarities between the platelet and sarcoplasmic reticulum $\mathrm{Ca}^{2+}$-ATPases. The two calcium pump proteins were activated by substrates in a similar way, and the activation processes were affected by two inhibitors in an equivalent manner. The part of the platelet $\mathrm{Ca}^{2+}$-ATPase hydrolytic cycle that describes substrate ligation can thus be modeled after the extensively studied sarcoplasmic reticulum $\mathrm{Ca}^{2+}$-ATPase hydrolytic cycle. The differences that were noted in this study between the platelet and sarcoplasmic reticulum $\mathrm{Ca}^{2+}$-ATPases in the values of the association constants for protein-substrate interactions could be due to structural differences in the two proteins that have been elucidated with limited proteolytic digestion studies (Fischer et al., 1985). In a more general sense, differences in the affinities of the calcium pump proteins for substrates could reflect differences in the physiological role of the protein in the source tissue, the sarcoplasmic reticulum $\mathrm{Ca}^{2+}$-ATPase being responsible for a rapid repetitive lowering of cytoplasmic calcium concentrations, while the primary function of the platelet $\mathrm{Ca}^{2+}$-ATPase is probably to maintain the cell in a resting state in the absence of activation.

\section{ACKNOWLEDGMENTS}

We are greatly indebted to David Barton for excellent technical assistance. 
Registry No. ATPase, 9000-83-3; Mg·ATP, 1476-84-2; Ca, 7440-70-2: quercetin, 117-39-5; calmidazolium, 57265-65-3.

\section{REFERENCES}

Adunyah, S. E., \& Dean. W. L. (1986) J. Biol. Chem. 261, 3122-3127.

Anderson, K., Coil, R., \& Murphy, A. (1984) J. Biol. Chem. 259, 11487-11490.

Carey, F, Menashi, S., \& Crawford, N. (1982) Biochem. J 204, 847-851.

Cornish-Bowden, A. (1979) Fundamentals of Enzyme Kinetics, Butterworths, London.

Cutler, L., Rodan, G., \& Feinstein, M. (1978) J. Gen. Physiol. $61,463-481$.

Dean, W. L. (1981) J. Biol. Chem. 259, 7343-7348.

Dean, W. L., \& Sullivan, D. M. (1982) J. Biol. Chem. 257, 14390-14394.

De Meis, L., \& Vianna, A. (1979) Annu. Rev. Biochem. 48 275-292.

Enouf, J., Bredoux, R., \& Levy-Toledano, S. (1984) Biochim. Biophys. Acta 772, 251-258.

Enyedi, A., Sarkadi, B., Foldes-Papp, Z., Monostory, S., \& Gardos, G. (1986) J. Biol. Chem. 261, 9558-9563.

Fabiato, A., \& Fabiato, F. (1979) J. Physiol. (Paris) 75, 463-505.

Fischer, T., Campbell, K. P., \& White, G. (1985) J. Biol. Chem. 260, 8996-9001.

Gould, G., East, J., Fraud, R., Whirter, H., Stefanoug, H., \& Lee, A. (1986) Biochem. J. 237, 217-227.

Ikemoto, N. (1982) Annu. Rev. Physiol. 44, 297-317.

Inesi, G., Kurzmack, M., Coan, C., \& Lewis, D. (1980) J. Biol. Chem. 255, 3025-3031.

Javors, M., Bowden, C., \& Ross, H. (1982) Biochim. Biophys. Acta 691, 220-226.

Käser-Glanzmann, R., Jakabova, M., George, J. N., \& Luscher, E. F. (1978) Biochim. Biophys. Acta 512,1-12.

Le Peuch, C. J., Le Peuch, D, A. M., Katz, S., Demaille, J.
G., Hincke. M. T., Bredoux, R., Enouf. J., Levy-Toledano S., \& Caen, J. P. (1983) Biochim. Biophys. Acta 731, 456-464.

MacLennan, D. (1970) J. Biol. Chem. 245, 4508-4518.

Martonosi, A. (1969) Biochem. Biophys. Res. Commun. 36 1039-1044.

Menashi, S., Davis, C., \& Crawford, N. (1982) FEBS Lett. 140, 298-302.

Moller, J., Lind, K., \& Anderson, J. (1980) J. Biol. Chem. 255, 1912-1920.

Neet, K., \& Green, M. (1977) Arch. Biochem. Biophys. 178 588-597.

Norby, J. (1971) Acta Chem. Scand. 25, 2717-2727.

Peterson, G. L. (1977) Anal. Biochem. 83, 346-356.

Reynolds, J, Johnson, E., \& Tanford, C. (1985) Proc. Natl. Acad. Sci. U.S.A. 82, 3658-3561.

Robblee, L., Shepro, D., \& Belamarich, F. A. (1973) J. Gen. Physiol. 61, 463-481.

Rodan, G. A., \& Feinstein, M. B. (1976) Proc. Natl. Acad. Sci. U.S.A. 73, 1829-1833.

Shoshan, V, \& MacLennan, D. (1981) J. Biol. Chem. 256 887-892.

Shoshan, V., Campbell, K., MacLennan, D., Frodis, W., \& Britt, B. (1980) Proc. Natl. Acad. Sci. U.S.A 77 4435-4438.

Statland, B. E, Heagan, B. M., \& White, J. G. (1969) Nature (London) 223, 51-522.

Tanford, C., Reynolds, J., \& Johnson, E. (1985) Proc. Natl. Acad. Sci. U.S.A. 82, 4688-4692.

The, R., \& Hasselback, W. (1972) Eur. J. Biochem. 28 357-363.

Vianna, A. (1975) Biochim. Biophys. Acta 410, 389-406. White, G., \& Raynor, S. (1982) Biochem. Biophys. Res. Commun. 104, 1066-1072.

Zubrzycka-Gaarn, E., MacDonald, G., Phillips, L., Jorgenssen, A., \& MacLennan, D. (1984) J. Bioenerg. Biomembr. 16, 441-464.

\section{CORRECTIONS}

${ }^{13} \mathrm{C}$ NMR Studies of Porphobilinogen Synthase: Observation of Intermediates Bound to a 280000-Dalton Protein, by Eileen K. Jaffe* and George D. Markham, Volume 26, Number 14 July 14, 1987, pages 4258-4264.

Page 4264. The following reference was inadvertently omitted from the reference list: Smith, D. J., Maggio, E. T, \& Kenyon, G. L. (1975) Biochemistry 14, 766-771.

Equilibrium and Dynamic Structure of Large, Unilamellar, Unsaturated Acyi Chain Phosphatidylcholine Vesicles. Higher Order Analysis of 1,6-Diphenyl-1,3,5-hexatriene and 1-[4(Trimethylammonio)phenyl]-6-phenyl-1,3,5-hexatrieneAnisotropy Decay, by Martin Straume and Burton J. Litman*, Volume 26, Number 16, August 11, 1987, pages 5113-5120.

Page 5114. In column 1, the sentence beginning on line 40 should read as follows: The model thus restricts TMA-DPH molecules to an orientation parallel to the bilayer normal.
Characterization of Alternate Reductant Binding and Electron Transfer in the Dopamine $\beta$-Monooxygenase Reaction, by Leslie C. Stewart and Judith Pollock Klinman*. Volume 26, Number 17, August 25, 1987, pages 5302-5309.

Page 5304. In Table I, the column headings should read as follows: column 2, $\left(V_{\max }\right)_{\mathrm{H}}\left(\mathrm{s}^{-1}\right)$; column $3,\left(V_{\max }\right)_{\mathrm{D}}\left(\mathrm{s}^{-1}\right)$; column 4, $\left(V / K_{\mathrm{DA}}\right)_{\mathrm{H}}\left(\mathrm{M}^{-1} \mathrm{~s}^{-1}\right)$; column $5,\left(V / K_{\mathrm{DA}}\right)_{\mathrm{D}}\left(\mathrm{M}^{-1} \mathrm{~s}^{-1}\right)$; column 6, $\left(V / K_{\mathrm{O} 2}\right)_{\mathrm{H}}\left(\mathrm{M}^{-1} \mathrm{~s}^{-1}\right)$; column $7,\left(V / K_{\mathrm{O}_{2}}\right)_{\mathrm{D}}\left(\mathrm{M}^{-1} \mathrm{~s}^{-1}\right)$.

Page 5308. In column 1, line 3, Table II should read Table I.

Thermodynamics of the Quenching of Tyrosyl Fluorescence by Dithiothreitol, by Joel K. Swadesh, Philip W. Mui, and Harold A. Scheraga*, Volume 26, Number 18, September 8, 1987, pages 5761-5769.

Page 5763. On the right-hand side of eq 1, the word "log" before the term in square brackets should be deleted. 